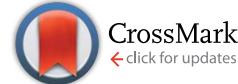

Cite this: RSC Adv., 2016, 6, 17759

Received 31st July 2015 Accepted 4th February 2016

DOI: $10.1039 / \mathrm{c} 5 \mathrm{ra} 15269 \mathrm{k}$

www.rsc.org/advances

\section{Biosensor-based detection of tuberculosis}

\begin{abstract}
Saurabh K. Srivastava, ${ }^{\star a b}$ Cees J. M. van Rijn ${ }^{b}$ and Maarten A. Jongsma ${ }^{a}$
Tuberculosis (TB), caused by Mycobacterium tuberculosis (M.tb.), is one of the most prevalent and serious infectious diseases worldwide with an estimated annual global mortality of 1.4 million in 2010. Diagnosis of TB in the developing world is very challenging due to the limited suitability of currently available techniques under tropical field conditions. M. tb. is a slowly growing Mycobacterium that takes around six to eight weeks to be detected via sensitive culture methods. There is also hardly any clinical symptom at an early stage of infection, thereby causing a delay in diagnosis and treatment, and the complexity of the disease is further increased by the emergence of multiple drug resistant (MDR) strains. A lot of work has been done over the last few decades to develop effective point of care diagnostic techniques that are cheap, robust and can be performed at high throughput in rural areas. However, despite considerable technical improvements reported from the lab, such economical fool-proof diagnostic assays are still lacking on the market. The objective of this review is to evaluate currently available biosensing techniques that are either already in use or under development for detection of TB. The focus of the review is on the emerging field of diagnostic biosensors that combine ligand capture and detection in a one-step assay. A comparison will also be made with conventional multistep techniques.
\end{abstract}

${ }^{a}$ Plant Research International, Wageningen UR, Droevendaalsesteeg 1, 6708 PB Wageningen, The Netherlands. E-mail: srivastava.saurabh@outlook.com

${ }^{b}$ Laboratory of Organic Chemistry, Wageningen UR, Dreijenplein 8, $6703 \mathrm{HB}$ Wageningen, The Netherlands

\section{Introduction}

\subsection{Background}

Tuberculosis (TB) is an age-old infectious disease of the human race, ${ }^{1,2}$ which has re-emerged globally as an important healthrelated issue, especially due to the emergence of multi-drug

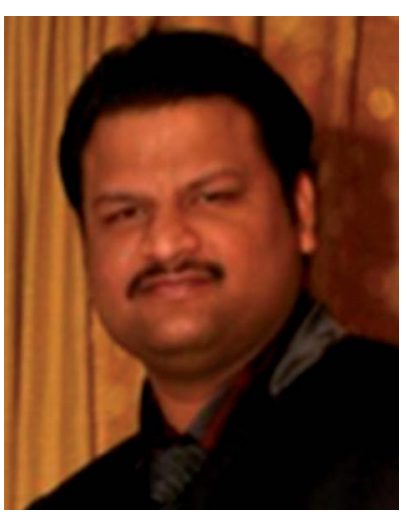

Dr ir. Saurabh Kumar Srivastava graduated from Allahabad Agricultural Institute-Deemed University, India in 2005 in Biotechnology (Genetic Engineering). After graduation he worked at the Department of Biotechnology, in Allahabad Agricultural Institute-Deemed University, India as an Assistant Professor, after which he went on to pursue an Erasmus Mundus dual master's degree program in Nanoscience as well as Molecular Bioengineering at the Delft university of Technology and Dresden University of Technology respectively. He received a $\mathrm{PhD}$ degree from Wageningen University on Biosensor based detection of tuberculosis biomarkers in 2014. His main research interest focuses on the development of electrochemical/optical biosensor devices for point-of-care diagnostic applications.

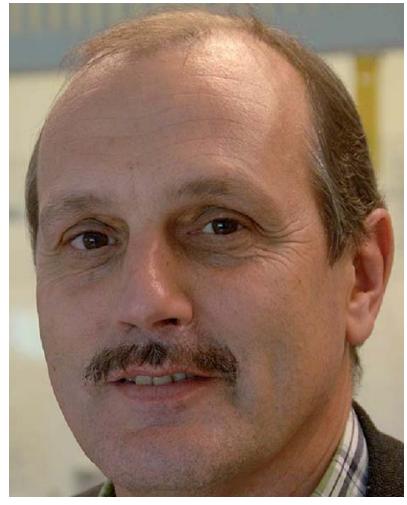

Prof. Dr Cees van Rijn graduated from Vrije Universiteit of Amsterdam in 1982 in Condensed Matter Physics, and received a Ph.D degree at the University of Leiden in 1989. He has worked at Philips Eindhoven and gained expertise in the semiconductor technology during the 'Megachip' project (19861991). He published a book 'Nano and Micro Engineered Membrane Technology', Elsevier (2004), that covers a broad spectrum of membrane science and technology, such as micro and nano filtration, biosensors, photonics, microbiology, controlled drug delivery, nanopatterning, micro contact printing, atomisation, and emulsification. He holds a chair on MicroFluidics and NanoTechnology for Agro, Food and Health at the University of Wageningen. His current interest is in the field of microfluidics and chemically interacting bioconjugated surfaces. 
resistant (MDR) strains. ${ }^{3,4}$ The specific characteristics of the Gram-negative bacillus, Mycobacterium tuberculosis (M.tb.) causing $\mathrm{TB}^{5}$ make it currently one of the most prevalent diseases. ${ }^{6}$ TB bacteria can remain inactive or in a dormant state for years without causing symptoms or spreading to other subjects, but as soon as the immune system of the host becomes weakened, the bacteria become active and infects mainly the lungs along with other parts of body. TB cases are further aggravated by other illnesses that affect the immune system, such as HIV, which is very prevalent in resource-poor countries. Unfortunately, in spite of sustained efforts at national and global levels, only limited success has been achieved in detection and management of TB worldwide. ${ }^{7,8}$ The main obstacles facing successful field detection and treatment of TB are:

(1) The omnipresence of the pathogen and disease across different continents, which complicates management and eradication programs. ${ }^{9}$ Most of the reported cases $(\sim 98 \%)$ are concentrated in developing countries, due to which TB is also known as a disease of poverty, with two-thirds of cases estimated to occur among people aged 15-59, adults in their most productive years. ${ }^{6}$ However, also developed Western countries continue to report TB cases. ${ }^{\mathbf{1 0}}$

(2) The high costs of the first line anti-TB drugs to treat TB (like isoniazid, rifampicin, pyrazinamide, ethambutol) bar their uses especially when multiple first line drugs need to be applied to suppress resistance. ${ }^{\mathbf{1 1 - 1 4}}$ This follow-up is often lacking in several affected countries like India. ${ }^{15-17}$

(3) Emergence of resistance in $M$. $t b$. against major first line chemotherapeutic agents has hindered the treatment of TB cases.

(4) To date, most diagnostic procedures rely largely on immuno-assays that are not sufficiently specific. $M$. $t b$. shares antigens to many other Mycobacterium species resulting in false positive cases in $\sim 35 \%$ of patients with active TB. ${ }^{18-20}$ Other techniques that have been employed like flow-cytometry, radiometric detection, latex agglutination etc. have their own

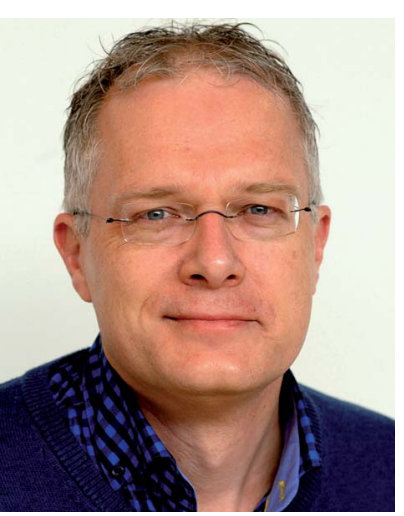

Dr ir. Maarten A. Jongsma graduated from Wageningen University in 1988 in Molecular Sciences. He received a PhD degree from Wageningen University on plantinsect interactions in 1995. Since then he has worked at Wageningen UR on topics involving protease inhibitors, terpenoids, insect behaviour, biosensors and $G$ protein-coupled receptors (http://www.wageningenur.nl/en/ Persons/Maarten-Jongsma.htm). He was coordinator of three EU projects, has published more than 90 papers and is the inventor of 10 patents. He has 8 publications in the biosensor field with some focusing on tuberculosis diagnostics (http:// scholar.google.nl/citations? user=7v4U8GwAAAAJ\&hl=en) and is currently programme director of NanoNextNL on 'Food process monitoring and product quality assessment' (http://uww.nanonextnl.nl). set of disadvantages which will be discussed in detail in the coming sections.

The objective of this study is to present a succinct review of the available biosensing techniques that are either already in use or under development in detection of TB. The focus of the review will be on emerging biosensor-approaches that are compared to conventional techniques. Special attention will be given to their potential for deployment under field conditions in resource-poor countries.

\subsection{Epidemiology}

The WHO Global TB Control Report 2012 reported that the WHO's Millennium Development Goal to halt the growth of the TB epidemic by 2015 is showing some success with a decrease of $2.2 \%$ observed between 2010 and 2011 for new TB cases, along with a $41 \%$ mortality rate decrease relative to 1990 . Between 1995 and 2011, 51 million people were successfully treated for TB, saving 20 million lives. Despite this progress, the global burden of TB remains enormous with 8.7 million new cases of TB were registered in 2011, out of which $13 \%$ patients were coinfected with HIV. The mortality in 2011 due to TB was 1.4 million, including almost one million deaths among HIVnegative individuals and 0.4 million among people who were HIV-positive. The distribution of TB cases also shows a genderdependence with men reporting more cases compared to females in all age groups and from every geographical region of the world. India and China together account for $40 \%$ whereas the African region contributes $24 \%$ of the world's TB cases. The statistics of the MDR cases in TB are alarming according to the WHO 2012 report. It reported resistance to more than one first line anti-TB drugs among $3.7 \%$ of new cases and $20 \%$ previously treated cases. In recognition of the problem, 26 nations have already listed MDR-TB as a top priority health programme and founded a global fund to support Directly Observed Therapy (DOT) to ensure the effectiveness of given medications. ${ }^{21-23}$

\subsection{Current TB diagnostics}

1.3.1 Immunological and microbiological tests. For the diagnosis of TB, five conventional tests are available:

(1) Smear microscopy: microscopy based smear tests are rapid, inexpensive, simple and relatively easy to perform methods for the detection of acid-fast bacterium such as $M$. $t b$. bacterium. Conventionally the Ziehl-Neelsen staining is utilized requiring a minimum of $1 \times 10^{4}$ bacterium per $\mathrm{ml}$ of sputum. ${ }^{24}$ Fluorescence microscopy utilizing auramine-rhodamine staining was found to be more sensitive though expensive, as it requires a fluorescence microscope. ${ }^{25}$ The fluorescence-based method is more sensitive as slides can be examined at lower magnification. ${ }^{24}$ Results from this method can be obtained within $\mathrm{h}$.

(2) Immunological assays like latex agglutination, ELISA, and Mantoux tests: in these tests, typically the binding of antibodies in serum to $M$. $t b$. antigens is tested. ${ }^{26,27}$ For example, in latex agglutination tests, the polystyrene (latex) beads are functionalized with antigens extracted from a pathogenic Mycobacterium, which are then reacted with serum samples. ${ }^{28}$ In case of 
a reaction, the latex beads coagulate showing a positive test. The sensitivity of these tests are not high enough. ${ }^{29}$ Hence, when the bacterial load is low, these tests will fail. Also, the serum could contain antibodies (due to vaccinations like Bacille-CalmetteGuérin/BCG) that might interfere with the tests adding further to the shortfalls of these assays.

(3) Radiometric detection test: in this type of test, the metabolic activity of $M$. $t b$. is detected radiologically. ${ }^{30}$ For example, $M$. $t b$. (and also some other Mycobacteria) are known to produce $\mathrm{CO}_{2}$ from carbon sources like glycerol or acetate. The important selective criterion is that $M$. $t b$. cannot form $\mathrm{CO}_{2}$ from glucose. This helps to differentiate $M$. $t b$. from other Mycobacterium sp. and bacteria. Utilizing this selective property, the capability of $M$. $t b$. in producing ${ }^{14} \mathrm{CO}_{2}$ from $14 \mathrm{C}$-U-glycerol or $14 \mathrm{C}$-U-acetate, but not from $14 \mathrm{C}-\mathrm{U}$-glucose is measured. Due to the technical complexity this technique is not suitable for developing countries.

(4) Flow cytometry test: in the last few years, use of flow cytometry has increased rapidly in the detection of TB cases. ${ }^{31-33}$ This technique is based on the ability of viable $M$. $t b$. bacterium to absorb fluorescein diacetate (FDA) and to hydrolyse it into fluorescein, which upon accumulation in metabolically active bacterium could successfully be detected by flow cytometry. The reproducibility is high and it does not require active cell division of mycobacteria. ${ }^{34,35}$ The technique, however, needs logistic support from a specialized laboratory that makes it difficult to implement in developing countries. ${ }^{36}$

(5) Cultivation detection tests (like MB/Bact, Bactec MGIT 960 systems): in these techniques, biological samples are selectively cultured on solid media to detect and quantify the presence of $M . t b .^{37-40}$ Although quite accurate, this technique is time consuming, as it requires a growth period of 9-42 days. It also requires a laboratory back up that complicates applications under field conditions in developing countries. ${ }^{40}$

1.3.2 Genotypic tests. DNA-based techniques are becoming increasingly important, especially for the detection of resistant strains of $M$. $t b$. They need a laboratory setting, however, so that for field use they do not yet represent a suitable method. The most popular techniques are the following:

(1) Polymerase chain reaction (PCR)-based techniques: PCR is one of the most sensitive methods to detect the presence of $M$. $t b$. strains, also sequencing of PCR amplified DNA fragments is the most direct technique of detecting codons responsible for resistance in $M . t b .^{41-43}$ PCR amplified DNA fragments are generally analysed by the following two methods:

(a) Electrophoresis: this method mainly relies on the difference in electrophoretic mobility of mutated DNA fragments of $M$. $t b$. especially of resistant strains. By electrophoretic techniques, PCR amplified DNA can be compared with the electrophoretic mobility of a wild type/reference $M$. $t b$. DNA, and thus caution for any resistance. ${ }^{44} \mathrm{~A}$ hetero-duplex analysis method has also been developed in recent years where strands with a single-base mismatch can easily be identified and separated utilizing conformation-sensitive gel electrophoresis from the strands containing no mismatches. ${ }^{\mathbf{4 5 , 4 6}}$

(b) Hybridization-based techniques: this type of technique relies on the hybridization of clinical DNA with complementary
DNA and the binding is then compared with the results of wild/ reference $M . t b$. DNA. $^{\mathbf{4 7}, 48}$ In case the complementary strand is sufficiently homologous, the binding of clinical DNA can be detected using ELISA readers. The hybridization can be done user-friendly on strips, microtiter plate as well as microarrays.

(c) Real-time PCR: with the help of fluorescently labelled DNA strands, it is possible to visualize the increase of the product in "real time". ${ }^{4-51}$ Different types of fluorescent labels have been applied in a diverse range of real-time PCR techniques, like TaqMan probes, ${ }^{50,52,53}$ Beacons ${ }^{54,55}$ and FRET probes. ${ }^{56,57}$

The main disadvantages of PCR-based tests are the relatively high costs of equipment and reagents. It also requires highly skilled personnel along with dedicated pre- and post-PCR rooms to avoid contamination. Even if it were less expensive, the technological and sample preparation complexities make it largely inappropriate for use in resource-poor settings.

\section{Biosensors in TB detection}

Considering the fact that $98 \%$ of all TB cases occur in developing countries without access to specialized laboratories, there is a strong need to develop alternative, simpler and lower cost techniques for TB diagnosis. Biosensors are analytical devices that transduce biochemical reactions/interactions of isolated enzymes, receptor proteins, antibodies, nucleic acids, organelles, whole cells or tissues with specific chemical compounds into an optical, thermal or electrical signal, which can be more easily measured and quantified. The main advantages of biosensors over conventional diagnostic techniques can be stated as follows:

(1) Technical advantage: in biosensors often a high level of device and capture/detection integration is achieved allowing single step detection.

(2) Ease of use: many of the designed biosensors are tailored with user-friendly interfaces connecting them to advanced instrumentation.

(3) Quick response: response time is typically a few minutes for most biosensors enabling rapid and better control over the measurement.

A general framework of different classes of biosensors that could be used for the detection of TB is given in Fig. 1 to guide the reader through the upcoming sections of the review and will be discussed in more detail within relevant sections.

\subsection{Electrochemical and electrical biosensors}

Electrochemical and electrical biosensors are among the most popular biosensors that are used today in detection of not only TB but also a large number of other diseases. ${ }^{6-62,129,130}$ The mechanism of detection relies on specific changes in electrical signals (conductance, impedance, potential, and capacitance) at a surface-functionalized electrode by either chemical reactions or physical interactions. For example, monoclonal antibodies raised against $M$. $t b$. cell wall components can be immobilized onto an electrode surface exposed to a suspension of $M$. $t b$. and detect the interaction between the $M$. $t b$. bacteria and the antibodies by a change of conductance. ${ }^{63}$ Similarly, an 


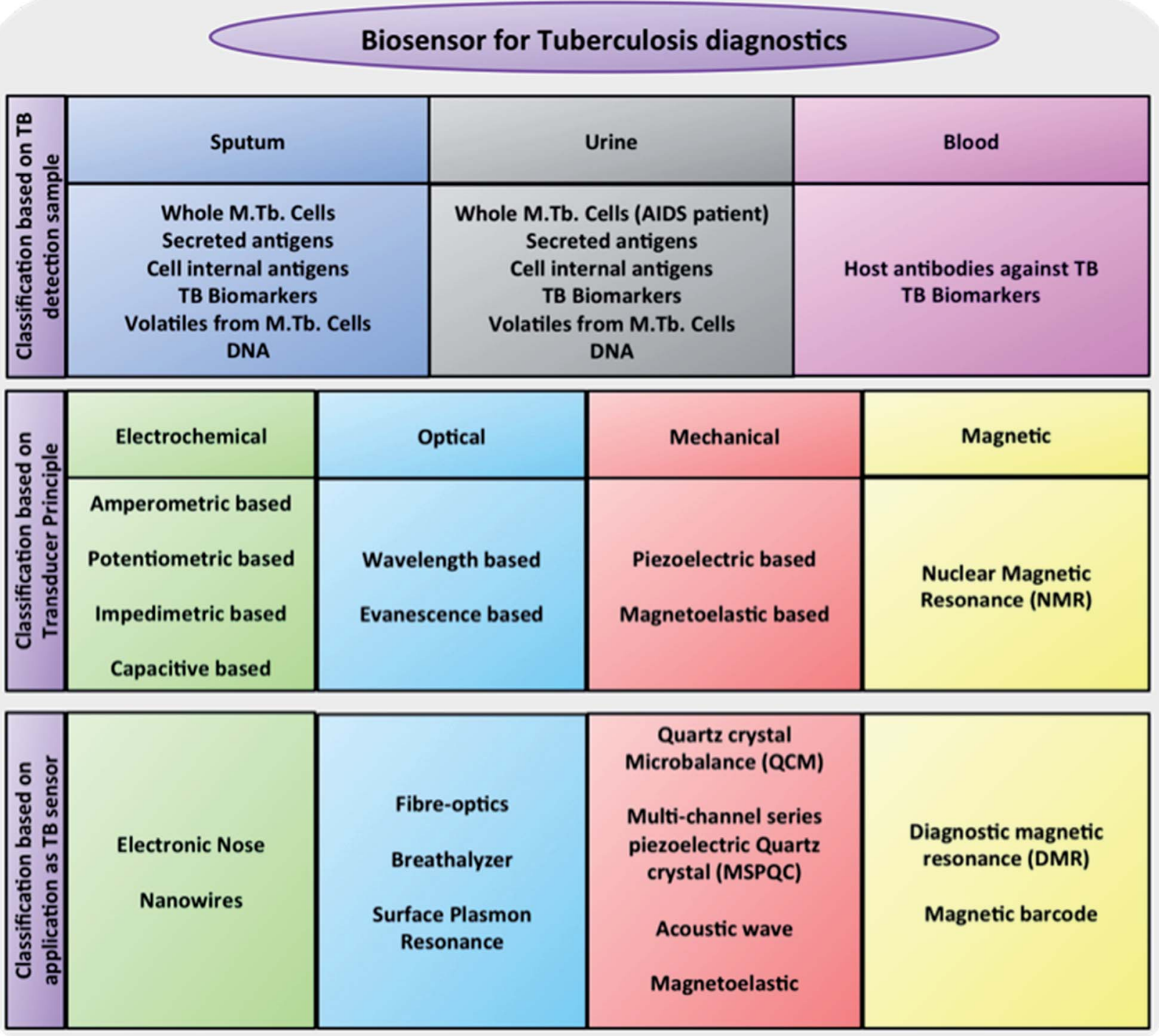

Fig. 1 Generic classification of biosensors tested as TB diagnostics. ${ }^{58,59}$

electrode-based DNA biosensor can also be made where certain probes that specifically bind to specific regions of $M$. $t b$. DNA are immobilized on the electrode..$^{62,129,130}$ As electrodes, carbon has often been used. ${ }^{60,62,64-66,129}$ These sensors are sensitive, flexible and allow a high degree of multiplexing, but they also present some disadvantages. Firstly, a constant $\mathrm{pH}$ and ion concentration of the reaction compartment is very critical, as they directly affect the baseline conductance of the electrodes. Secondly, the obtained electrical signal strictly depends on many molecular factors, like the positive or negative net charge or neutrality of the analyte $e t c$.

2.1.1 Electronic nose-based biosensors. Electronic "nose" type biosensors are designed to recognize volatile substances produced by $M$. $t b$. in liquid medium (Fig. 2) ${ }^{67-70,80}$ It basically consists of three main building blocks i.e. (i) a volatile gas chamber that passes the volatile molecule products over a sensor array, (ii) a pattern of more or less specific responses by the sensor array and (iii) a data analysis system to interpret the output pattern of the detection system. In an electrochemical transducer based system metal oxide semiconductors (MOSFETs like $\mathrm{ZnO}, \mathrm{MnO}, \mathrm{TiO}_{2}, \mathrm{SnO}_{2}$ ) or conducting polymers ${ }^{133}$ (like polypyrroles, polyanilines) coupled to the transducer are used. To obtain reliable signals, the humidity and temperature must be regulated well. The principle is based on the observation that $M$. $t b$. produces specific volatile organic compounds that are significantly different from the same produced by other Gram negative bacteria, like Mycobacterium avium, Mycobacterium scrofulaceum and Pseudomonas aeruginosa ${ }^{67}$ Electronic nose appliances have been used successfully to detect the presence of $M . t b .^{68}$ and efforts are also been made to develop it into commercial product. "Aeonose" is a commercial device based on the electronic nose concept that is currently under 


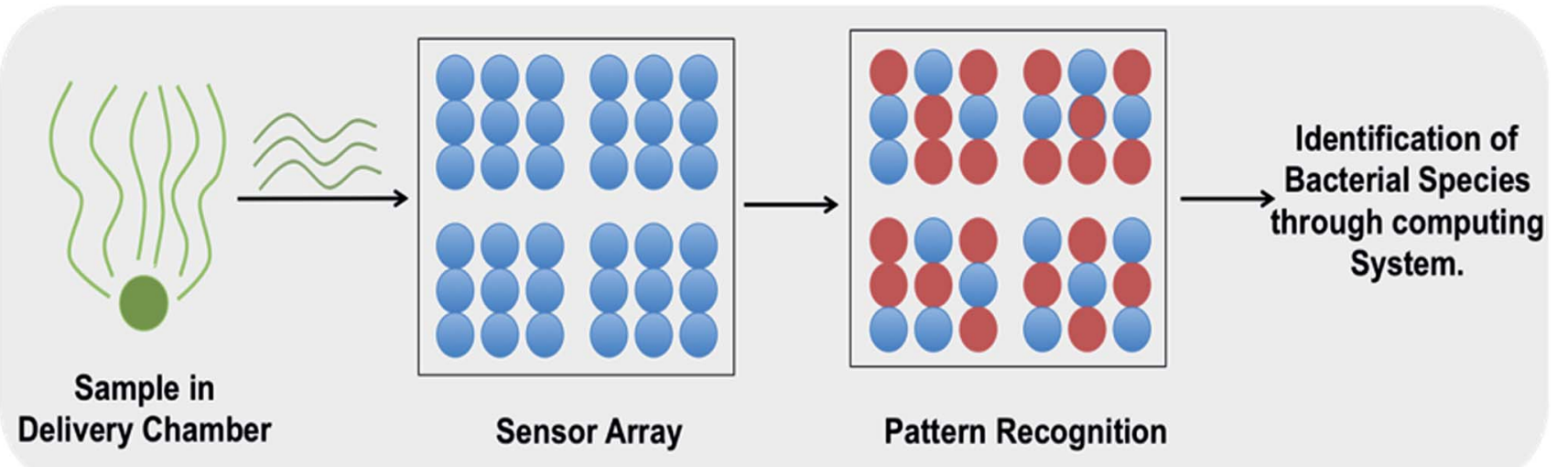

Fig. 2 An electronic nose based biosensor consisting of three main parts i.e. a sample delivery chamber, a detection array/pattern recognition system and a computing system for data analysis and result interpretation. This is a sensor assay where a specific pattern is produced upon interaction with volatile/gaseous by-products from specific bacterial species. ${ }^{71}$

development at a Dutch company The eNose company with successful clinical trials at locations such as Venezuela, Paraguay and Bangladesh. Although, these biosensors are of relatively low cost, non-invasive, long lasting with simple sampling methods and short response times, their relatively low sensitivity poses a major disadvantage for implementing them as a permanent diagnosis solution to TB diagnostics.

2.1.2 Nanowire-based biosensors. Biosensors built with nano-sized transducing elements are most prominently represented by silicon nanowires that operate as field effect transistors (FETs). A detailed discussion on the design of such FET sensors falls beyond the scope of this review. However, most commonly, a silicon nanowire with a low p-type doping is connected with a higher doped source and drain region, whereas the more heavily doped silicon support wafer is designed to serve as a back gate via an intermediate 100 to 500 $\mathrm{nm}$ thick silicon oxide layer. The backgate voltage controls the nanowire channel resistance and in case of a positive voltage $($ e.g. $+2 \mathrm{~V})$ a depletion layer is created in the silicon nanowire where the majority charge carriers (positively charged holes) are repelled, herewith creating a lower conductance (Fig. 3). For measurement, when a drain-source voltage is applied, a drain current $\left(I_{\mathrm{d}}\right)$ is generated between the source and drain regions that can then be measured and plotted against time. Any change in the amount of a (charged) target molecule binding to the surface gets reflected in a charge displacement in the wire (attraction or repellence of holes) and results in a variation in the $I_{\mathrm{d}}$ that can be interpreted against a calibration curve. Usually, silicon nanowires ${ }^{72,73}$ or carbon nanotubes ${ }^{6,74-76}$ are used to obtain the properties of nanowires. The testing system is often made on a microchip-like set up where the nanotubes are fixed along with surface functionalization with antibodies or antigens depending on the samples to be used. For example, boron-doped silicon nanowires were used to detect different bacterial antigens by the change of conductance after binding. ${ }^{77,78}$ Similarly, carbon nanotubes (both single and multi-walled) have been used to detect various antigens ${ }^{79}$ including $M$. $t b$. antigens or ssDNA specific for $M$. $t b .{ }^{66}$
The major advantage offered by this category of biosensors is its higher than normal sensitivity, because of two main factors i.e. (1) the size of the biological species/analyte to be detected is comparable to the size of the nanowire, hence the charge of the incoming species can sensitively control the conductivity of the charge carriers in the semiconductor material within the Debye length, ${ }^{82}(2)$ the wire represents a serial circuit where interaction at each receptor molecule can control the current flowing through the entire nanowire. ${ }^{83}$ The chemical nature of silicon and carbon wires and tubes allow a wide scope of surface functionalizations, which is an advantage compared to metal electrodes. However, the delicate surface functionalization and nature of silicon nanowires, makes it technologically much more challenging to actually design and implement these types of sensors ${ }^{84}$ thus limiting the technique merely to the proof of concept stage.

\subsection{Optical biosensors}

2.2.1 Fibre-optic biosensors. Light propagating through an optical fibre consists of two components i.e. the light propagating through the core of the fibre and the exponentially decaying evanescent field outside the core of the fibre (Fig. 4). In case of total internal reflection (TIR), the intensity of the

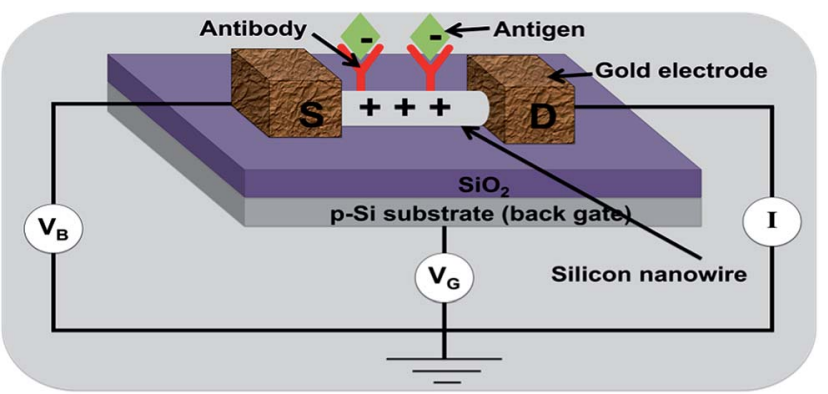

Fig. 3 A silicon nanowire based biosensor: a change in conductance of an antibody-functionalized nanowire is measured upon binding of the antigen. ${ }^{81}$ 
reflected light does not decay rapidly as only a very small amount of light passes through the thickness of the tube and hence not able to interact with the fibre's surroundings. The decay of the transmitted light (evanescent wave) is exponentially related to the distance travelled (d) outside the core and is typically 100 to $200 \mathrm{~nm}$. This rate of decay of the evanescent wave can be reduced by decreasing the thickness of the cladding layer (walls) of the tube, making the method suitable for sensing applications. In this situation, the evanescent wave interacts with the fibres' surrounding, causing an energy flow that could activate fluorophores bound to the outer surface of the fibre tube. The emitted light from the fluorophores can then also be detected using a spectrophotometer. These sensors can be tailor-made to detect specific pathogens. For example, $M$. $t b$. produces niacin, which after reaction with cyanogen bromide and aniline produces a compound of yellow colour. ${ }^{132}$ In another example, TB-specific biomarkers such as LAM, early secretory antigen target 6 (ESAT 6) and antigen 85 complex (Ag85) were utilized for the detection of TB in sandwich assay on waveguide-based platform. ${ }^{127}$ Hence, a $M$. $t b$.-rich sputum sample will contain high levels of niacin which after reaction with cyanogen bromide and aniline will produce a colour which can be detected by fibre-optics. Similar types of sensitive fibreoptics-based biosensors for TB detection have also been reported elsewhere ${ }^{85-88}$ Multiplexing is required to render such detection platforms more reliable.

Another interesting class of biosensors with good potential for TB detection is the so-called optical ring resonance (ORR) detectors. The principles of optical ring resonance are complex and fall beyond the scope of this review. In summary, these ORR systems are based on total internal reflection and constructive interference..$^{90}$ Recently, such ORR detectors could be designed on lab-on-a-chip platforms ${ }^{91,92}$ with multiple parallel channels with one channel coated with specific antibody (test channel) and others coated with non-specific antibodies (reference channel). With binding of the antigens with their specific antibodies, there are changes observed in total internal reflection and simultaneous interference patterns which are recorded by a CCD camera and compared to the data obtained from reference channels. Pending the availability of highly specific antibodies to $M$. $t b$. antigens, these ORR detectors may be of potential in early detection of TB although the surface functionalization has the same challenges as in case of nanowire functionalization, because the core material of the fibre is mostly silicon based.

2.2.2 Surface plasmon resonance (SPR)-based biosensors. Surface plasmon resonance (SPR) is an optical principle frequently used in biosensors. Surface plasmons (evanescent waves) are produced when a polarized light is incident at the back of a thin film of noble metals like gold and silver. The angle of reflection changes depending on mass bound to the surface on the other side. The other side of these noble metals are therefore coated with bio-recognition elements or receptor molecules that interact with an analyte molecule present in a liquid sample. A light wave can excite surface plasmons at metal-dielectric interface only when the component of the light wave vector parallel to the interface matches with that of the surface plasmon. For this, the light wave vector needs to be enhanced so that it matches the surface plasmons, as the real part of the propagation constant is always larger than that provided by the light wave vector in the dielectric. Usually attenuated total reflection methods with a prism are employed for excitation of the surface plasmons. A light wave passing through an optical prism is allowed to fall on the metal film of about $50 \mathrm{~nm}$ thick at an angle of incidence that is larger than the critical angle for the prism-dielectric system. Now this light

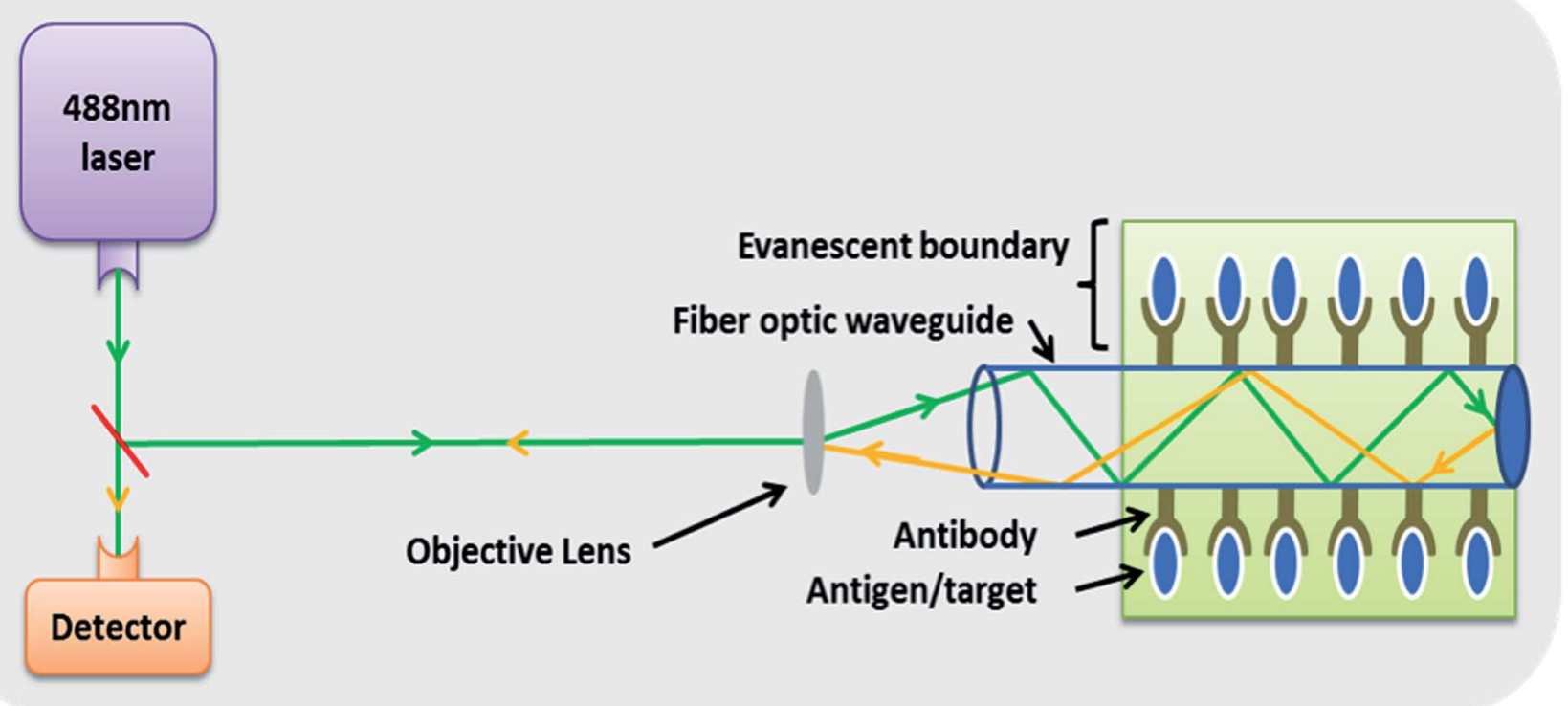

Fig. 4 A fibre optics based biosensor where specific binding at the exterior of fibre optic waveguide via specific antibodies is measured by determining the change in the angle of reflection of the incident light. The system works using the principle of evanescence. ${ }^{89}$ 
is totally reflected producing evanescent waves propagating along the metal film. A portion of the light energy is transferred into energy of these surface plasmons and is dissipated in the metal field resulting in a drop of intensity of reflected light. The coupling conditions can be fulfilled for multiple combinations of angle of reflection and the wavelength. Therefore, a characteristic dip associated with the excitation of surface plasmons can be observed both in angular and spectral domains. The instrumentation of SPR consists of a convergent monochromatic beam source directed onto the prism coupler, over which the sample containing the metal layer modified with receptor molecule is passed (Fig. 5).

For a certain angle of incidence, the coupling between the light wave and the surface plasmon occurs, thereby generating a change in refractive index at the sensor surface giving rise to a change in angular position of the SPR dip, which is measured by position-sensitive photo-detector. SPR analysis is sensitive to environmental conditions like temperature and buffer concentration. Thus, a parallel background measurement is employed to correct for the change in refractive index caused by these background effects. Gold surfaces immobilized with antibodies that bind $M$. $t b$. antigens or complex was successfully used to detect TB. ${ }^{94-101}$ The sensitivity of the system to detect $M$. $t b$. antigen (CFP-10 antigen) in tissue fluid was $100 \mathrm{ng} \mathrm{ml}{ }^{-1},{ }^{102}$ and for $M . t b$. complex was $30 \mathrm{ng} \mu^{-1} \cdot{ }^{97}$ The sensitivity of the SPR system could be further enhanced as demonstrated by Chen et al., where they detected the TB antigen CFP-10 in sandwich assay by coupling the secondary sandwich antibodies with nanoparticle thus obtaining sensitivity down to $0.1 \mathrm{ng} \mathrm{ml}^{-1} \cdot{ }^{128}$ SPR based biosensors are already used for detection of various pathogens, including bacteria like Salmonella sp., however, the costs are high and trained personnel are required to operate them. ${ }^{103}$

2.2.3 Breathalyzer biosensors. Breathalyzer sensors have specifically been developed to diagnose pulmonary TB in patients. Typically, in these types of sensors the patients are asked to cough in a masked bag-like structure containing a collection tube (usually $10 \mathrm{~cm}$ in length and $3.5 \mathrm{~cm}$ in width) after administration of a nebulized dose of saline. ${ }^{\mathbf{1 0 4 , 1 0 5}}$ The samples thus collected are distributed across the surface of a coated prism at the bottom of the glass tube. This prism surface is coated with $M$. $t b$. specific antibody and fluorescent peptide epitopes. ${ }^{\mathbf{1 0 4}}$ The peptide analogue comprises artificially modified peptide sub-sequences of the T-cell epitope from $M$. $t b$. Ag85B. ${ }^{106}$ The antibody has a higher affinity for TB bacterium compared to the fluorescent peptide analogues, which enables a competition assay on such platforms. ${ }^{104}$ In the presence of TB bacterium, the fluorescent-coated analogues are displaced by TB bacterium and the diode laser of the measuring device interrogates this biochemical process. The sensitivity of the system for detection of $M$. $t b$. cells was $50-75 \mathrm{CFU} \mathrm{ml}{ }^{-1} .^{104}$ The biosensors are portable, rapid and sensitive encouraging their use in outdoor clinics in the developing World. The collection tube is cheap and easy to dispose after one use per patient. ${ }^{104} \mathrm{~A}$ commercial device based on the breathalyser principle is currently under development at the UK based company Rapid Biosensor Systems Ltd. (RBS-TB Breathalyser). Although the

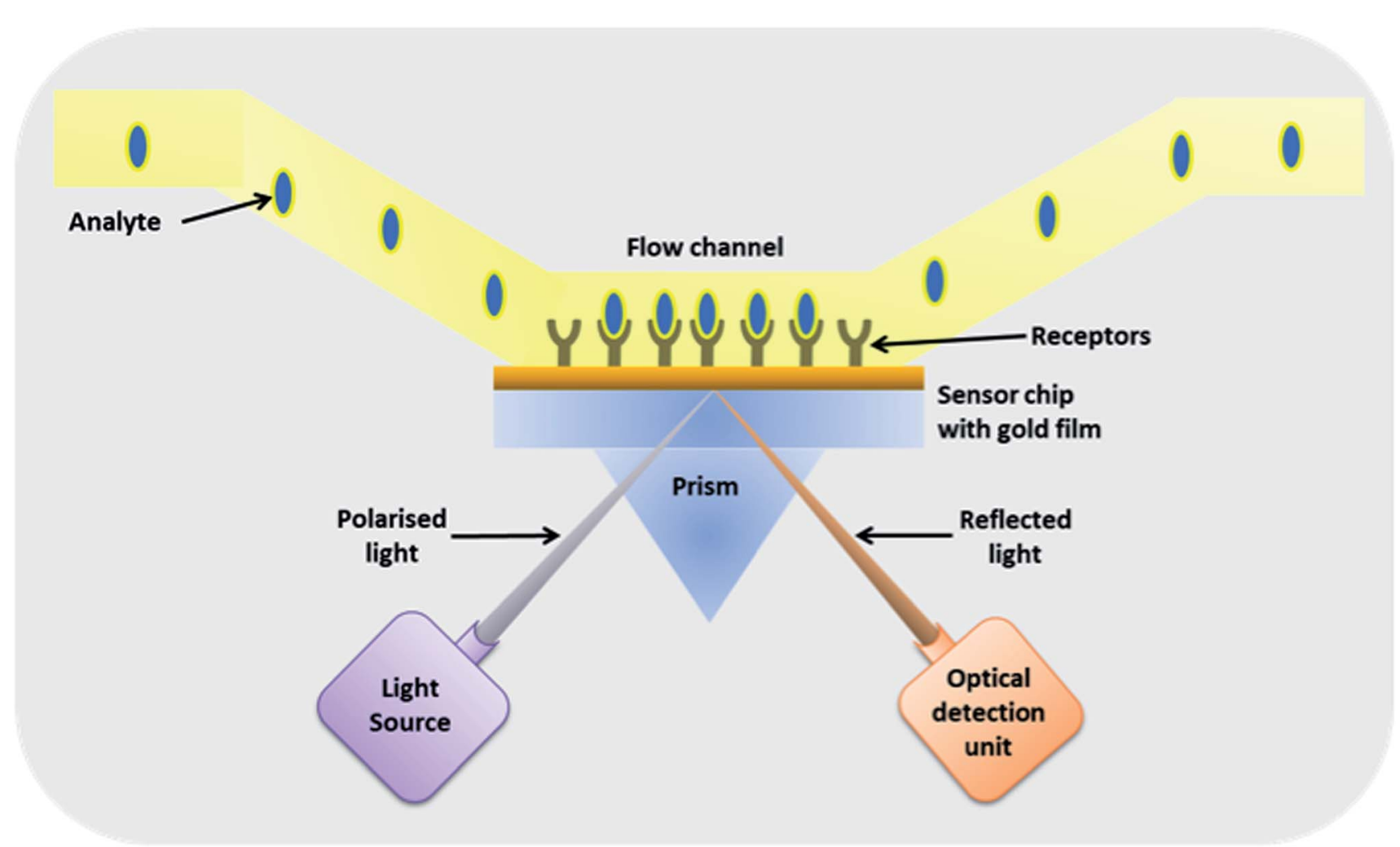

Fig. 5 A surface plasmon resonance based biosensor. In this type of biosensor, a thin gold plate is functionalized with antibodies that upon binding to the antigen cause a change in the angle of reflection of the polarised light incident at the other side of the gold film. ${ }^{93}$ 
device has been validated in clinical trials in India and Ethiopia, there were a few cases of false positives. ${ }^{\mathbf{1 0 4}}$ After further optimization, characterization and validation, the sensing method has the potential to be become into a sensitive diagnostic alternative for the current methods to detect tuberculosis.

\subsection{Mechanical biosensors}

2.3.1 Piezoelectric quartz crystal biosensor. Piezoelectric quartz crystal biosensors are based on the Sauerbray equation ( $\Delta F=-2.3 \times 10^{6} F^{2} \Delta M / A$, where $\Delta F$ is change in frequency, $F$ is resonant frequency, $\Delta M$ is change in deposited mass and $A$ is area of electrode), which shows that change in frequency of the crystal is directly related to the change in deposited mass over the electrodes. Due to this unique resonant frequency property of quartz crystals, any changes in resonating mass by the binding of specific biomolecules or microbes and bacteria like M.tb. can be sensitively detected (Fig. 6). ${ }^{107-109,131}$ Piezoelectric biosensors of three types have been described: quartz crystal microbalance (QCM), multi-channel series piezoelectric quartz crystal sensor (MSPQC) and acoustic wave biosensor.

2.3.1.1. Quartz crystal microbalance (QCM). In QCM systems applied to $\mathrm{TB}$, the crystal electrode was first coated with protein A followed by binding of an anti-TB-cells antibody (rabbit IgG against $M$. $t b$.) and then incubated with weakened TB cells. Binding of $M$. $t b$. cells on the crystal electrodes was monitored in real time and the frequency shift was calculated. The sensi-

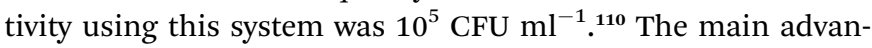
tage of QCM lies in the fact that it is fast, reusable (after washing), label-free, requires minimal sample preparation and is easily operated. The major disadvantage lies in the fact that the density, temperature, viscosity and electrical conductivity of the sample may affect the results and require calibration correction and that it is relatively insensitive.

2.3.1.2. Multi-channel series piezoelectric quartz crystal sensor (MSPQC). In the MSPQC system, there are eight sample detectors along with a microprocessor and a data output system. The system relies on detection of volatiles produced by the growth of M. $t b$. such as $\mathrm{NH}_{3}$ and $\mathrm{CO}_{2}$. These volatiles cause an impedance change when they are absorbed by a $\mathrm{KOH}$ absorbing solution, which in turn will change the oscillating frequency. The limit of

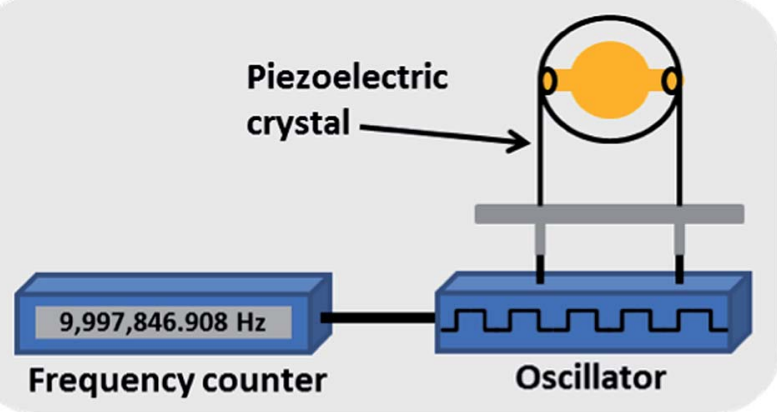

Fig. 6 A piezoelectric quartz crystal based biosensor where the change in resonating frequency of a piezoelectric crystal is measured. The resonance frequency of the crystal shows a change after binding of antigens with specific antibodies immobilised on the crystal. ${ }^{110}$ detection with this system is $10^{7} \mathrm{CFU} \mathrm{ml} \mathrm{ml}^{-1}$ at the time of detection. ${ }^{111}$ Apart from being time consuming involving a laborious $M$. $t b$. culture process (eight days in case of a low $M$. $t b$. burden), another major drawback of this system is the sample pre-treatment required to remove contamination with other bacteria.

2.3.1.3. Acoustic wave biosensor. Acoustic wave biosensors rely upon acoustic waves propagating near the surface of a piezoelectric crystal. The sensor electrically produces a mechanical wave that is sensitive to any change or binding at the piezoelectric crystal and then transduces the mechanical output waves back into an electrical signal, which is compared with the input electrical signal for changes in amplitude, phase, and frequency. ${ }^{112}$ In one application apart from the acoustic signal also the conductivity change (impedance) of the medium over the crystal was measured. Here the conductivity change due to growth of $M$. $t b$. cells and by-product production was studied. ${ }^{\mathbf{1 1 3 , 1 1 4}}$ The limit of detection with this bulk acoustic wave impedance biosensor was $2 \times 10^{3} \mathrm{CFU} \mathrm{ml}^{-1}$. The disadvantage of the system is the time consuming and laborious $M$. $t b$. culture process that reduced the applicability for field uses.

2.3.2 Magnetoelastic biosensors. Magnetoelastic biosensors possess a magneto-elastic strip, often made up of ferromagnetic alloys comprising iron, boron, nickel and molybdenum. Capture molecules (like antibodies) that can bind target molecules, microbes or viruses are immobilized on the strip (Fig. 7). ${ }^{115-117}$ Exposure of the magnetoelastic strip to a varying external magnetic field causes the magnetoelastic strip to resonate at a specific (fundamental) frequency. The fundamental resonant frequency for longitudinal vibration of a thin ribbon like strip vibrating in its basal plane is given by the equation.

$$
f=\sqrt{\frac{E}{\rho\left(1-\sigma^{2}\right) 2 L}}
$$

where $E$ denotes modulus of elasticity, $\sigma$ is the Poisson's ratio, $\rho$ is the mass density of the sensor material, and $L$ is the longitudinal dimension of the sensor. The change in resonant frequency also depends on mass change when the initial mass, temperature and humidity are constant and is given by the equation.

$$
\Delta f=-\frac{f}{2}\left(\frac{\Delta m}{M}\right)
$$

where $f$ is the initial resonance frequency, $M$ is the initial mass, $\Delta m$ is the mass change, and $\Delta f$ is the shift in the resonant frequency of the sensor. ${ }^{118}$ It is due to this dependence on mass change, that upon binding of antigens or $M$. $t b$. bacteria to the antibody, there is a shift in fundamental resonant frequency, which is often monitored wirelessly on a frequency counter.

The advantages of these types of sensors over SPR-based sensors are their ease of use as the sensors are (i) freely hanging inside a sample solution, (ii) do not require complicated integration with microfluidics pumps and (iii) do not produce a complex signal. The fundamental resonating frequency of the strip immersed in liquid (culture media) can also be altered due to the consumption of nutrients. $M$.tb. in the 

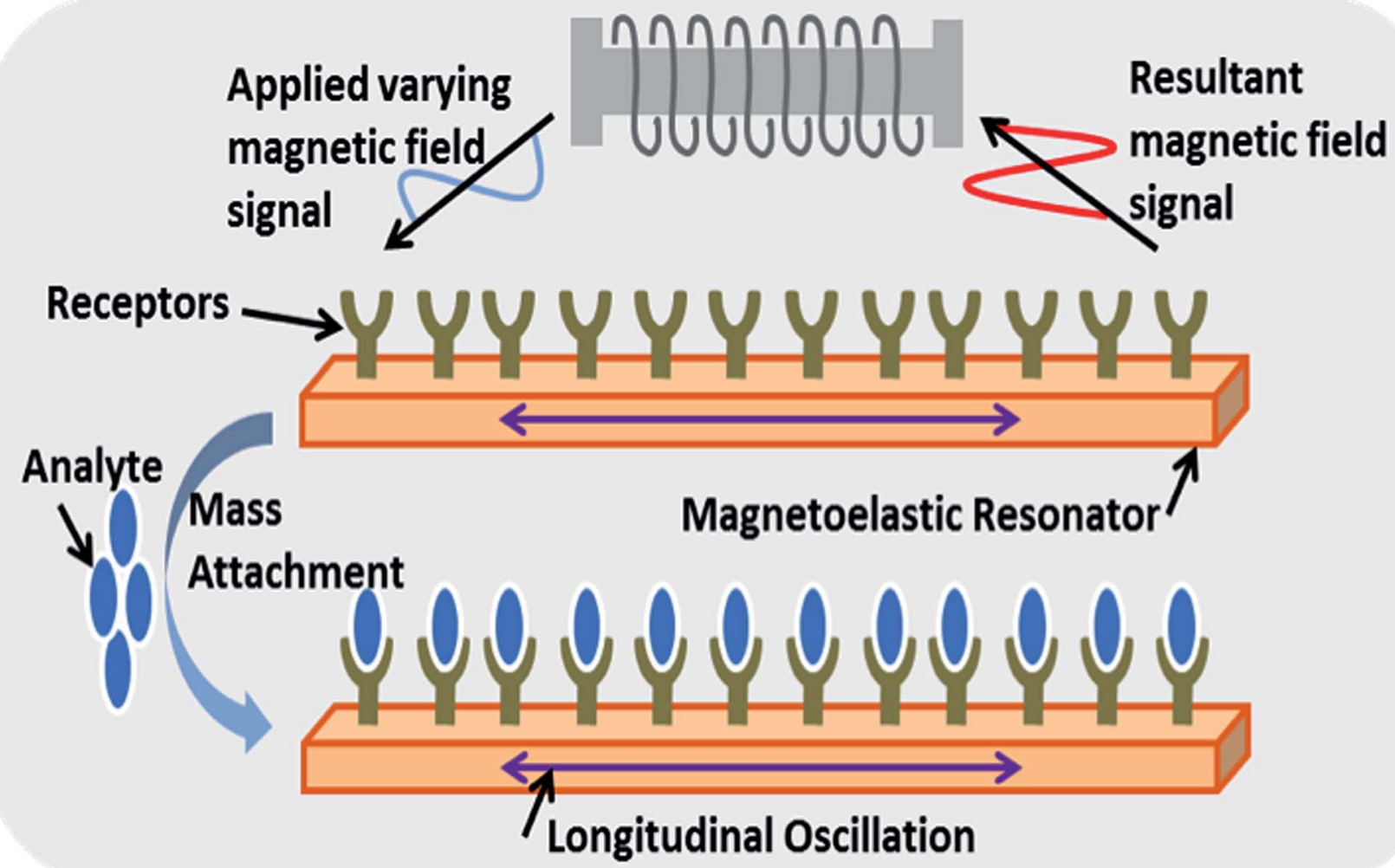

Fig. 7 A magnetoelastic biosensor where the change in basal resonating frequency of a magnetoelastic strip as a result of binding of antigens with specific antibodies under varying magnetic fields is measured in order to detect analyte. ${ }^{119}$

liquid media, upon proliferation decomposes macromolecule into by products (such as ammonia, carbon dioxide, organic acid) thereby causing a change in the physical properties of the culture that can then be detected with the help of such biosensors. A suitable calibration curve must be made to detect a specific $M$. $t b$. signature. ${ }^{117}$ The sensor resonant frequency shift upon immersion in liquid is given by the equation

$$
f=-\frac{\sqrt{\pi f_{0}}}{2 \pi \rho_{\mathrm{s}} d}\left(\eta \rho_{1}\right)^{1 / 2}
$$

where $f_{0}$ is the resonant frequency of the sensor in air, $\rho_{\mathrm{s}}$ and $d$ are the density and thickness of the sensor, $\eta$ and $\rho_{1}$ are the density and viscosity of the liquid, respectively. Under liquid medium, the shear wave created due to the sensor vibration reduces the oscillation of the sensor. The detection limit of this biosensor can be as low as $10^{4} M$. $t$. cells per ml. ${ }^{117}$

\subsection{Magnetic biosensors}

2.4.1 Diagnostic magnetic resonance (DMR). DMR system is an automated, high-throughput miniaturized lab-on-a-chip scale adaptation of conventional nuclear magnetic resonance (NMR). Its principle is based on detection of changes in the spin relaxation time of surrounding water molecules i.e. when antibodies coated on mono-dispersed nanoparticle binds to target (M.tb. cells) forming a cluster or aggregate and thus becomes more efficient in dephasing the nuclear spin of surrounding water molecules, thereby causing a decrease in spin-spin relaxation time. It consists of four miniaturized modules i.e. a microcoil array for applying the magnetic field, a small permanent magnet, feedback based read out electronics for temperature compensation and a microfluidic network for automated sample injection. ${ }^{120,121}$ Capture antibody functionalized magnetic nanoparticles are used which can specifically detect the Mycobacterium cells. By virtue of its operating principle, highly sensitive $\left(20 \mathrm{CFU} \mathrm{m}{ }^{-1}\right)$ magnetic measurements can be done on easier to handle turbid and unprocessed sputum samples without pre-treatment or false positives as biological samples show virtually no magnetic background. ${ }^{122,123}$ The decreased assay time, small sample volumes, versatility and multiplicity make it suitable for point of care diagnostics. The low cost of the setup and disposable chip could be an advantage for use in remote clinics and hospitals in the developing world. In 2013, the DMR was further miniaturized for very small volume sample detection $(2 \mathrm{ml})$ and rapid, high throughput operations in point of care settings. ${ }^{124}$ This approach has been used to analyse varied bacterial mixtures with specific probes. Another improvement is the amplification of 16S rRNA from total RNA extracted from whole bacterial cells by asymmetric RT-PCR. Single-strand DNA amplified from 16S rRNA is then captured by magnetic beads conjugated with capture probe. After which hybridization with magnetic NPs (MNPs) coated with detection probe is done to form a magnetic sandwich complex detectable using $\mu$ NMR system. Though the magneto-genetic assay has not been utilized yet for TB 
Table 1 Comparison of different biosensor modalities for M.tb. detection

\begin{tabular}{|c|c|c|c|c|c|}
\hline \# & Transducer & Sensing technique & Sample analysed & Detection limit & References \\
\hline \multirow[t]{2}{*}{2.1} & Electrochemical & Electronic nose & M.tb. produced volatile compounds & Not available & Pavlou et al. ${ }^{67}$ \\
\hline & & Nanowire/nanotubes & M.tb. specific ssDNA & Not available & Das et $a l .^{66}$ \\
\hline \multirow[t]{4}{*}{2.2} & Optical & Fibre-optics & M.tb. produced organic compounds & Not available & Pariwono et al. ${ }^{132}$ \\
\hline & & SPR & CFP 10 M.tb. antigen or protein & $0.1 \mathrm{ng} \mathrm{ml}-1$ & Chen et al. ${ }^{128}$ \\
\hline & & & complexes & $30 \mathrm{ng} \mathrm{ml}^{-1}$ & Duman et al. ${ }^{97}$ \\
\hline & & Breathalyzer & M.tb. cells & 50-75 CFU per ml & McNerney et al. ${ }^{104}$ \\
\hline \multirow[t]{4}{*}{2.3} & Mechanical & QCM & M.tb. cells & $10^{5}$ cells per $\mathrm{ml}$ & He et al. ${ }^{108}$ \\
\hline & & MSQC & $\begin{array}{l}\text { Volatiles produced by } M . t b \text {. cells } \\
\text { growth }\left(\mathrm{NH}_{3}, \mathrm{CO}_{2}\right)\end{array}$ & $10^{7} \mathrm{CFU}$ per $\mathrm{ml}$ & Ren et al. ${ }^{111}$ \\
\hline & & Acoustic Wave & M.tb. cells & $2 \times 10^{3} \mathrm{CFU} / \mathrm{ml}$ & He et al. ${ }^{114}$ \\
\hline & & Magnetoelastic & M.tb. cells by-products & $10^{3}$ cells per $\mathrm{ml}$ & Pang et al. ${ }^{117}$ \\
\hline \multirow[t]{2}{*}{2.4} & Magnetic & DMR & M.tb. cells & $20 \mathrm{CFU} \mathrm{ml}^{-1}$ & Lee et $a .^{123,126}$ \\
\hline & & Magnetic barcode & RNA from $M . t b$. cells & $100 \mathrm{CFU} \mathrm{ml}^{-1}$ & Liong et $a l . .^{125}$ \\
\hline
\end{tabular}

detection, it has a strong potential to be applied for clinical and point of care settings. ${ }^{124}$

2.4.2 Magnetic barcode platform. A novel platform for the detection of nucleic acids is based on a magnetic bar coding strategy. PCR-amplified mycobacterial genes can be sequencespecifically captured on microspheres, labelled by magnetic nanoprobes and detected by nuclear magnetic resonance. This significant improvement of $\mu$ NMR in terms of size and design has resulted in glass slide sized magnetic barcode platform detection. The sample volume to be analysed passes through a microfluidics channel enclosed by an electromagnetic coil. This sensing component eliminates the use of permanent magnets. ${ }^{125}$ The coil functions as a sensing element where a shift in relaxation time is measured using a feedback of the readout electronics. ${ }^{120,121}$ The platform also integrates lab on a chip PCR for assay optimization. For TB detection the total RNA is extracted from the TB cells and the 16S rRNA is amplified by asymmetric real time-PCR to single-strand DNA which is then immobilised on conjugated beads, followed by hybridizing with magnetic nanoparticles (MNPs) and coated with a detection probe to form a magnetic sandwich complex. The complex thus formed is allowed to pass through microfluidic channels, where it is detected. ${ }^{125}$ In an example using 92-nt fadE15 amplicons, they showed that magnetic bar coding assays had a strong magnetic signal within $1 \mathrm{~min}$ of labelling at $37^{\circ} \mathrm{C}$. The costs of the device can potentially be scaled down to $<\$ 200$ in contrast with existing diagnosis instruments that cost over $\$ 10000 . .^{125}$

\section{Conclusions}

TB remains one of the major unresolved global health problems, especially in the developing parts of the world, predominantly due to the complexity of a proper and economic affordable diagnosis and treatment in time along with recently arising issues like multiple drug resistance and other allied infections that decrease body immunity, like HIV. Current technologies for diagnosis are either too insensitive, too laboratory intensive or utilize expensive detection modules, which are all challenges in resource poor settings. Most of the biosensors (except Electronic nose and Breathalyzer) discussed in the present review are still at the developmental stage and lack clinical validation with real TB samples from patients. The test material in the reviewed published literature, mainly consists of genomic material, M.tb. protein, $M$. $t b$. by-products or whole $M$. $t b$. cells that are pure and tested under conditions far removed from patient samples. All sensor methods have their own merits and potential problems with respect to sample preparation, requirement of skilled personnel to handle the sample, sensitivity or cost. Moreover, since the sensitivity of each system is expressed in different units and not linked to the bacterial count, benchmarking these diagnostic platforms is not currently possible. An overview of the analyzed sample and detection limits of different biosensors is shown in Table 1. With WHO's aim to completely eliminate TB by 2050, development of techniques for early and accurate detection of $\mathrm{TB}$ is crucial. To build an effective biosensor for TB detection, criteria that need to be fulfilled are: (1) cost-effectiveness (2) high sensitivity (3) reliability (no false positives) (4) portability and (5) disposability. Unfortunately, designing a biosensor with all these advantages has not yet been completely successful, as each attempt has specific drawbacks. It is a challenge to satisfy all these needs in a single biosensing device. Nevertheless, the advances in nanosensors and other upcoming technologies reviewed here, suggest that biosensors to detect TB can be expected to play a larger role in the near future. Such platforms will also need to solve issues around sample collection and preparation. Currently most diagnosis techniques available utilize sputum samples as test sample, which due to its high viscosity and sticky nature is very difficult to work with. Hence other sources like blood or urine should also be considered as test samples. Lack of reliable and tested biomarkers in those samples is, however, an issue that needs attention.

\section{Future outlook}

For effective TB detection in resource-poor settings the field of biosensors has very strong potential. However, key to the development of such biosensors is a focus on both the sample preparation steps from biofluids (e.g. blood, sputum) and the 
functionalisation of non-fouling surfaces with antibodies, aptamers etc. that are sensitive enough to allow early diagnosis in the future. The existing portfolio of potential sensing techniques all have their own pros and cons and it is not yet possible unfortunately to select one as most promising, because they have not yet been developed and successfully validated into a marketed products that can be benchmarked.

\section{Acknowledgements}

The authors acknowledge the financial support obtained from the Dutch Technology Foundation STW under the Project number 10058.

\section{References}

1 M. Gandy and A. Zumla, Soc. Sci. Med., 2002, 55, 385.

2 J. M. Grange, M. Gandy, P. Farmer and A. Zumla, International Journal of Tuberculosis and Lung Disease, 2001, 5, 208.

3 N. S. Shah, A. Wright, G. H. Bai, L. Barrera, F. Boulahbal, N. Martin-Casabona, F. Drobniewski, C. Gilpin, M. Havelkova, R. Lepe, R. Lumb, B. Metchock, F. Portaels, M. F. Rodrigues, S. Rusch-Gerdes, A. Van Deun, V. Vincent, K. Laserson, C. Wells and J. P. Cegielski, Emerging Infect. Dis., 2007, 13(3), 380-387.

4 J. C. Palomino, A. Martin, M. Camacho, H. Guerra, J. Swings and F. Portaels, Antimicrob. Agents Chemother., 2002, 46(8), 2720-2722.

5 N. A. Kruh, J. Troudt, A. Izzo, J. Prenni and K. M. Dobos, PLoS One, 2010, 5, e13938.

6 J. F. Murray, Am. J. Respir. Crit. Care Med., 2004, 169, 1181.

7 P. Nahid, M. Pai and P. C. Hopewell, Proc. Am. Thorac. Soc., 2006, 3, 103.

8 Expert Group Meeting Report, WHO, 2014, p. 1.

9 S. Murray, Can. Med. Assoc. J., 2006, 174, 33.

10 L. P. Ormerod, Br. Med. Bull., 2005, 73-74, 17.

11 C. Mitnick, J. Bayona, E. Palacios, S. Shin, J. Furin, F. Alcántara, E. Sánchez, M. Sarria, M. Becerra, M. C. Fawzi, S. Kapiga, D. Neuberg, J. H. Maguire, J. Y. Kim and P. Farmer, N. Engl. J. Med., 2003, 348, 119.

$12 \mathrm{~J}$. A. Caminero, International Journal of Tuberculosis and Lung Disease, 2006, 10, 829.

13 P. Isaakidis, H. S. Cox, B. Varghese, C. Montaldo, E. Da Silva, H. Mansoor, J. Ladomirska, G. Sotgiu, G. B. Migliori, E. Pontali, P. Saranchuk, C. Rodrigues and T. Reid, PLoS One, 2011, 6, e28066.

14 C. Colijn, T. Cohen, A. Ganesh and M. Murray, PLoS One, 2011, 6, e18327.

15 S. S. Shin, J. J. Furin, F. Alcantara, J. Bayona, E. Sanchez and C. D. Mitnick, Emerging Infect. Dis., 2006, 12, 687.

16 C.-H. Lee, M.-C. Lee, H.-H. Lin, C.-C. Shu, J.-Y. Wang, L. N. Lee and K. M. Chao, PLoS One, 2012, 7, e37978.

17 C. Mulenga, D. Mwakazanga, K. Vereecken, S. Khondowe, N. Kapata, I. C. Shamputa, H. Meulemans and L. Rigouts, BMC Public Health, 2010, 10, 756.
18 A. Bekmurzayeva, M. Sypabekova and D. Kanayeva, Tuberculosis, 2013, 93, 381.

19 A. Somoskovi, J. E. Hotaling, M. Fitzgerald, V. Jonas, D. Stasik, L. M. Parsons and M. Salfinger, J. Clin. Microbiol., 2000, 38, 2743.

20 S. Singh, J. Singh, S. Kumar, K. Gopinath, V. Balooni, N. Singh and K. Mani, PLoS One, 2012, 7(7), r40213.

21 S. C. Cavalcante, E. C. C. Soares, A. G. F. Pacheco, R. E. Chaisson and B. Durovni, International Journal of Tuberculosis and Lung Disease, 2007, 11, 544.

22 A. Anuwatnonthakate, P. Limsomboon, S. Nateniyom, W. Wattanaamornkiat, S. Komsakorn, S. Moolphate, N. Chiengsorn, S. Kaewsa-Ard, P. Sombat, U. Siangphoe, P. A. Mock and J. K. Varma, PLoS One, 2008, 3, e3089.

23 A. D. Harries, A. Jahn, R. Zachariah and D. Enarson, PLoS Med., 2008, 5, e124.

24 J. C. Palomino, Eur. Respir. J., 2005, 26, 339.

25 K. R. Steingart, M. Henry, V. Ng, P. C. Hopewell, A. Ramsay, J. Cunningham, R. Urbanczik, M. Perkins, M. A. Aziz and M. Pai, Lancet Infect. Dis., 2006, 6, 570.

26 K. Minton, Nat. Rev. Immunol., 2003, 3, 355.

27 J. G. Fernández, I. Fernández-de-Mera, L. E. Reyes, M. C. Ferreras, V. Pérez, C. Gortazar, M. Fernández and J. F. García-Marín, J. Vet. Diagn. Invest., 2009, 21, 102.

28 S. Bhaskar, J. N. Banavaliker and M. Hanif, FEMS Immunol. Med. Microbiol., 2003, 39, 235.

29 S. Bhaskar, J. N. Banavaliker, K. Bhardwaj and P. Upadhyay, J. Immunol. Methods, 2002, 262, 181.

30 D. Satana, A. Y. Coban and M. Uzun, J. Clin. Microbiol., 2010, 48, 4291.

31 R. Dinser, M. Fousse, U. Sester, K. Albrecht, M. Singh, H. Köhler, U. Müller-Ladner and M. Sester, Rheumatology, 2008, 47, 212.

32 L. Cosmi, L. Maggi, V. Santarlasci, F. Liotta, F. Frosali, R. Angeli, M. Mazzetti, A. Vultaggio, A. Matucci, E. Maggi, S. Romagnani and F. Annunziato, Int. Arch. Allergy Immunol., 2007, 143(1), 1-9.

33 L. Li, D. Qiao, X. Fu, S. Lao, X. Zhang and C. Wu, PLoS One, 2011, 6, e20165.

34 M. D. Bonecini-Almeida, Mem. Inst. Oswaldo Cruz, 2000, 95, 491.

35 M. Piuri, W. R. Jacobs Jr and G. F. Hatfull, PLoS One, 2009, 4, e4870.

36 C. Pina-Vaz, S. Costa-de-Oliveira and A. G. Rodrigues, J. Med. Microbiol., 2005, 54, 77.

37 J. J. Yan, A. H. Huang, S. H. Tsai, W. C. Ko, Y. T. Jin and J. J. Wu, Diagn. Microbiol. Infect. Dis., 2000, 37, 25.

$38 \mathrm{H}$. Saitoh and N. Yamane, Rinsho Biseibutshu Jinsoku Shindan Kenkyukai Shi, 2000, 11, 19.

39 F. Alcaide, M. A. Benítez, J. M. Escribà and R. Martín, J. Clin. Microbiol., 2000, 38, 398.

40 M. Garrigo, L. M. Aragon, F. Alcaide, S. Borrell, E. Cardenosa, J. J. Galán, J. Gonzalez-Martín, N. MartinCasabona, C. Moreno, M. Salvado and P. Coll, J. Clin. Microbiol., 2007, 45, 1766.

41 L. Y. Itani, M. A. Cherry and G. F. Araj, J. Med. Liban., 2005, 53, 208. 
42 N. Kobayashi, T. G. Fraser, T. W. Bauer, M. J. Joyce, G. S. Hall, M. J. Tuohy and G. W. Procop, Arch. Pathol. Lab. Med., 2006, 130, 1053.

43 D. V. Cousins, S. D. Wilton, B. R. Francis and B. L. Gow, J. Clin. Microbiol., 1992, 30, 255.

44 R. M. Shawar, F. A. el-Zaatari, A. Nataraj and J. E. Clarridge, J. Clin. Microbiol., 1993, 31, 61.

45 G. A. Thomas, D. L. Williams and S. A. Soper, Clin. Chem., 2001, 47, 1195.

46 A. M. Mohamed, D. R. Bastola, G. P. Morlock, R. C. Cooksey and S. H. Hinrichs, J. Clin. Microbiol., 2004, 42, 1016.

47 V. J. Tevere, P. L. Hewitt, A. Dare, A. Keen, J. P. Spadoro and K. K. Young, J. Clin. Microbiol., 1996, 34, 918.

48 C. T. Michelon, F. Rosso, K. B. Schmid, R. D. Sperhacke, M. M. Oliveira, A. L. Kritski, L. Jr Rezende, E. R. Costa, A. W. Ribeiro, M. Verza, P. I. Cafrune, M. S. Silva, D. Kuhleis, A. Zaha and M. L. Rossetti, Mem. Inst. Oswaldo Cruz, 2011, 106, 194.

49 C. Drosten, M. Panning and S. Kramme, Clin. Chem., 2003, 49, 1659.

50 F. Broccolo, P. Scarpellini, G. Locatelli, A. Zingale, A. M. Brambilla, P. Cichero, L. A. Sechi, A. Lazzarin, P. Lusso and M. S. Malnati, J. Clin. Microbiol., 2003, 41, 4565.

51 K. Baba, S. Pathak, L. Sviland, N. Langeland, A. A. Hoosen, B. Asjo, A. M. Dyrhol-Riise and T. Mustafa, Diagn. Mol. Pathol., 2008, 17, 112.

52 J. H. Kim, Y. J. Kim, C.-S. Ki, J.-Y. Kim and N. Y. Lee, J. Clin. Microbiol., 2011, 49, 173.

53 S. A. Bustin, J. Mol. Endocrinol., 2002, 29, 23.

54 J. Papaparaskevas, D. P. Houhoula, A. Siatelis and A. Tsakris, J. Clin. Microbiol., 2008, 46, 3177.

55 P. Kumar, K. Nath, B. Rath, M. K. Sen, P. Vishalakshi, D. S. Chauhan, V. M. Katoch, S. Singh, S. Tyagi, V. Sreenivas and H. K. Prasad, J. Mol. Diagn., 2009, 11, 430.

56 M. J. Taylor, M. S. Hughes, R. A. Skuce and S. D. Neill, J. Clin. Microbiol., 2001, 39, 1272.

57 T. Luo, L. L. Jiang, W. M. Sun, G. Fu, J. Mei and Q. Gao, J. Clin. Microbiol., 2011, 49, 3132.

58 S. Sang, W. Zhang and Y. Zhao, Review on the Design Art of Biosensors, 2013.

59 R. Thusu, Sensors Online (Strong Growth Predicted for Biosensors Market), 2010.

60 Z. Dai, F. Yan, J. Chen and H. Ju, Anal. Chem., 2003, 75, 5429.

61 T. G. Drummond, M. G. Hill and J. K. Barton, Nat. Biotechnol., 2003, 21, 1192.

62 M. Das, G. Sumana, R. Nagarajan and B. D. Malhotra, Appl. Phys. Lett., 2010, 96, 133703.

63 M. Diaz-Gonzalez, M. B. Gonzalez-Garcia and A. CostaGarcia, Biosens. Bioelectron., 2005, 20, 2035.

64 C. Fernandez-Sanchez, M. B. Gonzalez-Garcia and A. CostaGarcia, Biosens. Bioelectron., 2000, 14, 917.

65 O. Ouerghi, A. Senillou, N. Jaffrezic-Renault, C. Martelet, H. Ben Ouada and S. Cosnier, J. Electroanal. Chem., 2001, 501, 62 .
66 M. Das, C. Dhand, G. Sumana, A. K. Srivastava, N. Vijayan, R. Nagarajan and B. D. Malhotra, Appl. Phys. Lett., 2011, 99, 143702.

67 A. K. Pavlou, N. Magan, J. M. Jones, J. Brown, P. Klatser and A. P. Turner, Biosens. Bioelectron., 2004, 20, 538.

68 A. D. Wilson and M. Baietto, Sensors, 2011, 11, 1105.

69 R. Freeman, R. Goodacre, P. R. Sisson, J. G. Magee, A. C. Ward and N. F. Lightfoot, J. Med. Microbiol., 1994, 40, 170.

70 G. Keshri and N. Magan, J. Appl. Microbiol., 2000, 89, 825.

71 A. P. Turner and N. Magan, Nat. Rev. Microbiol., 2004, 2, 161.

72 T. M. H. Lee, Sensors, 2008, 8, 5535.

73 F. Shen, M. Tan, Z. Wang, M. Yao, Z. Xu, Y. Wu, J. Wang, X. Guo and T. Zhu, Environ. Sci. Technol., 2011, 45, 7473.

74 D. R. S. Jeykumari and S. S. Narayanan, J. Nanosci. Nanotechnol., 2009, 9, 5411.

75 L. X. Zhou, X. X. He, D. G. He, K. M. Wang and D. L. Qin, Clin. Dev. Immunol., 2011, 193963.

76 M. Pumera, Methods Mol. Biol., 2010, 625, 205.

77 G. Zheng, X. P. A. Gao and C. M. Lieber, Nano Lett., 2010, 10, 3179.

78 J. Lund, R. Mehta and B. A. Parviz, Nanomedicine, 2006, 2, 230.

79 S. N. Kim, J. F. Rusling and F. Papadimitrakopoulos, $A d v$. Mater., 2007, 19, 3214.

80 S. Chatterjee, M. Castro and J. F. Feller, J. Mater. Chem. B, 2013, 36, 4563.

81 K.-I. Chen, B.-R. Li and Y.-T. Chen, Nano Today, 2011, 6, 131.

82 M. M. Gregersen, M. B. Andersen, G. Soni, C. Meinhart and H. Bruus, Phys. Rev. E: Stat., Nonlinear, Soft Matter Phys., 2009, 79, 066316.

83 G. F. Zheng, F. Patolsky, Y. Cui, W. U. Wang and C. M. Lieber, Nat. Biotechnol., 2005, 23, 1294.

84 N. Kazemi-Zanjani, E. Kergrene, L. J. Liu, T. K. Sham and F. Lagugne-Labarthet, Sensors, 2013, 13, 12744.

85 K. A. Denton, M. F. Kramer and D. V. Lim, J. Rapid Methods Autom. Microbiol., 2009, 17, 17.

86 B. M. Hewitt, N. Singhal, R. G. Elliot, A. Y. H. Chen, J. Y. C. Kuo, F. Vanholsbeeck and S. Swift, Environ. Sci. Technol., 2012, 46, 5414.

87 R. J. Yan, N. S. Lynn, L. C. Kingry, Z. J. Yi, R. A. Slayden, D. S. Dandy and K. L. Lear, Appl. Phys. Lett., 2011, 98, 13702.

88 A. Leung, P. M. Shankar and R. Mutharasan, Sens. Actuators, $B, 2007,125,688$.

89 C. A. J. Gouveia, J. M. Baptista and P. A. S. Jorge, Refractometric Optical Fiber Platforms for Label Free Sensing, 2013.

90 H. Zhu, I. M. White, J. D. Suter, P. S. Dale and X. Fan, Opt. Express, 2007, 15, 9139.

91 I. M. White, J. Gohring and X. Fan, Opt. Express, 2007, 15, 17433.

92 M. Baaske and F. Vollmer, ChemPhysChem, 2012, 13, 427. 93 M. A. Cooper, Nat. Rev. Drug Discovery, 2002, 1, 515.

94 A. Rachkov, S. Patskovsky, A. Soldatkin and M. Meunier, Talanta, 2011, 85, 2094. 
95 S. C. Hsieh, C. C. Chang, C. C. Lu, C. F. Wei, C. S. Lin, H. C. Lai and C. W. Lin, Nanoscale Res. Lett., 2012, 7, 180.

96 N. Prabhakar, K. Arora, S. K. Arya, P. R. Solanki, M. Iwamoto, H. Singh and B. D. Malhotra, Analyst, 2008, 133, 1587.

97 M. Duman and E. Piskin, Biosens. Bioelectron., 2010, 26, 908.

98 J. G. Huang, C. C. K. Hung, H. C. Lai, C. K. Lee, S. M. Lin, P. Feng and C. W. Lin, IEEE Engineering in Medicine and Biology Magazine, 2004, 26, 2553.

99 M. Duman, M. O. Caglayan, G. Demirel and E. Piskin, Sens. Lett., 2009, 7, 535.

100 A. K. Trilling, H. de Ronde, L. Noteboom, A. van Houwelingen, M. Roelse, S. K. Srivastava, W. Haasnoot, M. A. Jongsma, A. Kolk, H. Zuilhof and J. Beekwilder, PLoS One, 2011, 6, e26754.

101 S. K. Srivastava, V. J. B. Ruigrok, N. J. Thompson, A. K. Trilling, A. J. R. Heck, C. van Rijn, J. Beekwilder and M. A. Jongsma, PloS One, 2013, 8, e64040.

102 S. C. Hong, H. Chen, J. Lee, H.-K. Park, Y. S. Kim, H. C. Shin, C. M. Kim and T. J. Park, Sens. Actuators, B, 2011, 156, 271.

103 J. Homola, S. S. Yee and G. Gauglitz, Sens. Actuators, B, 1999, 54, 3.

104 R. McNerney, B. A. Wondafrash, K. Amena, A. Tesfaye, E. M. McCash and N. J. Murray, BMC Infect. Dis., 2010, 10, 161.

105 T. B. Begg, I. D. Hill and L. C. Nickolls, Br. Med. J., 1964, 1, 9. 106 A. S. Mustafa, F. A. Shaban, A. T. Abal, R. Al-Attiyah, H. G. Wiker, K. E. Lundin, F. Oftung and K. Huygen, Infect. Immun., 2000, 68, 3933.

107 X. Mi, F. He, M. Xiang, Y. Lian and S. Yi, Anal. Chem., 2011, 84, 939.

108 F. J. He and L. D. Zhang, Anal. Sci., 2002, 18, 397.

109 F. J. He, L. D. Zhang, J. W. Zhao, B. L. Hu and J. T. Lei, Sens. Actuators, B, 2002, 85, 284.

110 A. Kumar and N. M. Ravindra, J. Miner. Met. Mater. Soc., 2000, 52(10), 14.

111 J. L. Ren, F. J. He, S. L. Yi and X. Y. Cui, Biosens. Bioelectron., 2008, 24, 403.

112 T. M. Gronewold, Anal. Chim. Acta, 2007, 603, 119.

113 G. N. Ferreira, A. C. da-Silva and B. Tome, Trends Biotechnol., 2009, 27, 689.

114 F. J. He, J. W. Zhao, L. D. Zhang and X. N. Su, Talanta, 2003, 59, 935.
115 C. Ruan, K. Zeng, O. K. Varghese and C. A. Grimes, Anal. Chem., 2003, 75, 6494.

116 R. Zhang, M. I. Tejedor-Tejedor, C. A. Grimes and M. A. Anderson, Anal. Chem., 2007, 79, 7078.

117 P. Pang, Q. Cai, S. Yao and C. A. Grimes, Talanta, 2008, 76, 360.

118 Q. Y. Cai, A. Cammers-Goodwin and C. A. Grimes, J. Environ. Monit., 2000, 2, 556.

119 W. Shen, S. Li, M.-K. Park, Z. Zhang, Z. Cheng, V. Petrenko and B. A. Chin, J. Electrochem. Soc., 2012, 159(10), B818.

120 D. Issadore, C. Min, M. Liong, J. Chung, R. Weissleder and H. Lee, Lab Chip, 2011, 11, 2282.

121 J. B. Haun, C. M. Castro, R. Wang, V. M. Peterson, B. S. Marinelli, H. Lee and R. Weissleder, Sci. Transl. Med., 2011, 3, 71.

122 A. L. Chun, Nat. Nanotechnol., 2009, 4, 698.

123 H. Lee, E. Sun, D. Ham and R. Weissleder, Nat. Med., 2008, $14,869$.

124 H. J. Chung, C. M. Castro, H. Im, H. Lee and R. Weissleder, Nat. Nanotechnol., 2013, 8, 369.

125 M. Liong, A. N. Hoang, J. Chung, N. Gural, C. B. Ford, C. Min, R. R. Shah, R. Ahmad, M. Fernandez-Suarez, S. M. Fortune, M. Toner, H. Lee and R. Weissleder, Nat. Commun., 2013, 4, 1752.

126 H. Lee, T.-J. Yoon and R. Weissleder, Angew. Chem., Int. Ed., 2009, 48, 5657.

127 H. Mukundan, S. Kumar, D. N. Price, S. M. Ray, Y. J. Lee, S. Min, S. Eum, J. Kubicek-Sutherland, W. K. Grace, A. S. Anderson, S. H. Hwang, S. N. Cho, L. E. Via, C. III Barry, R. Sakamuri and B. I. Swanson, Tuberculosis, 2012, 92(5), 407.

128 H. Chen, F. Lie, K. Koh, J. Lee, Z. Ye, T. Yin and L. Sun, Microchim. Acta, 2013, 180(5), 431.

129 A. Miodek, N. Mejri, M. Gomgnimbou, C. Sola and H. KorriYoussoufi, Anal. Chem., 2015, 87(18), 9257.

130 C. Liu, D. Jiang, G. Xiang, L. Liu, F. Liu and X. Pu, Analyst, 2014, 139(21), 5460.

131 P. A. Marin, L. E. Botero, J. A. Robledo, A. M. Murillo, R. A. Torres, Y. J. Montagut, E. Pabon and M. Jaramillo, Acta Biol. Colomb., 2015, 20(1), 40731.

132 A. M. Pariwono, T. Lo, C. S. Lim, S. X. Wang and Y. W. Chan, Journal of Biomedical \& Pharmaceutical Engineering, 2007, 1, 27.

133 R. Fend, A. H. J. Kolk, C. Bessan, P. Buijtels, P. R. Klatser and A. C. Woodman, J. Clin. Microbiol., 2006, 44(6), 2039. 